\title{
EXISTENTIAL POSTDISCIPLINARITY: PERSONAL JOURNEYS INTO TOURISM, ART, AND FREEDOM
}

\author{
TOMAS PERNECKY,* ANA MARÍA MUNAR,† AND BRIAN WHEELLER $\ddagger$ \\ *School of Hospitality and Tourism, Auckland University of Technology, Auckland, New Zealand \\ †Department of International Economics and Management, Copenhagen Business School, \\ Copenhagen, Denmark \\ $\ddagger$ Department of International Tourism, Breda University of Applied Sciences (NHTV), \\ Breda, the Netherlands
}

\begin{abstract}
Postdisciplinarity makes claims on ontological, epistemic, and methodological levels, but it is inevitably a personal philosophical stance. This article represents an existentialist approach to the discourse on postdisciplinarity, offering reflective narratives of three academics. Tomas Pernecky discusses creativity, criticality, freedom, and methodological and epistemic pluralism; Ana María Munar reveals her journey of epistemological awakening; and Brian Wheeller underscores the importance of researchers' subjective and emotive voice. Jointly, the authors depict postdisciplinarity as an invitation to conceptual and interpretive eclecticism, critical analysis, and creative problem solving.
\end{abstract}

Key words: Constructionism; Existential; Identity; Knowledge; Subjective; Truth

Introduction

In the introduction to this special issue, it has been suggested that postdisciplinarity is best conceived as a new direction that is starting to emerge within the fields of Tourism, Hospitality, and Event Studies. Postdisciplinarity has a handful of supporters, considerable opposition, and a vast number of undecided scholars who are yet to make sense of it. In contrast to other contributions in this special issue, we have chosen to offer an unorthodox approach to postdisciplinarity. Our article is based on personal reflections of three academics who consider it important to share their own stories and experiences in order to provide a different angle through which certain ideas about postdisciplinarity can be advanced-hence the title, "Existential Postdisciplinarity: Personal Journeys Into Tourism, Art, and Freedom.”

The article is divided into three parts. In the first section, Hot Spot Istanbul, Tomas Pernecky speaks of creativity, criticality, freedom, methodological and epistemic pluralism, and semantically diverse readings of our worlds. Ana María Munar then 
reveals her own journey of epistemological awakening and ponders whether it is possible to be an academic without a discipline. Munar brings up a number of issues, including the notion of "artistic integrity" and the "internalization of otherness." Both Pernecky and Munar draw on their experiences of visiting an art exhibition; however, each emphasizes different points in regard to postdisciplinarity while keeping to the overarching message of this article. In the last part, Brian Wheeller encourages researchers to use their subjective and emotive voice as well as their own background, life events, and valuable personal insights. All three authors hold that these are the building blocks that shape who we become. The message we wish to advance is that it is not less worthy-in a scholarly sense- - to produce work that is personal, subjective, and emotional, as our life journeys influence our academic work, our interests, and also the ways in which we make sense of objects, places, and experiences.

We should note that the style we follow does not conform to the traditional guidelines of academic writing. For example, there is no conclusion to neatly sum-up and interpret the ideas for the reader. We strove to make our points clear in each of the contributions, and we hope that they come through. Like a good poem or a painting, one does not need to be given a detailed description - being given the "correct" way to make sense. There is something terribly mechanical about guidelines for seeing, understanding, and interpreting the world. For this reason, we left the creative process of interpretation and intentionality up to the reader. To this end, we envisage our article as a creative response to postdisciplinarity. Nonetheless, that does not make this contribution less valuable or less importanta point we emphasize jointly. All creative processes, all thinking, and all actions are intersubjective activities. By tapping into the personal, the shared, and the coconstructed, we can investigate the varied accounts of ourselves, of others, and of tourism.

Finally, there are several broader ideas connecting our views that should be stated upfront. Postdisciplinarity surpasses the boundaries of disciplinary thinking and opens up the possibility to question the established phenomena-touristic or otherwise-we take for granted. We do not claim that disciplinarity (including other varieties such as inter-/multi-/cross-disciplinarity) is wrong or unimportant, or that postdisciplinarity is to replace these in a linear fashion; our vision for postdisciplinarity is to make the act of inquiring less firmly embedded in traditional systems of thought. Postdisciplinarity is mainly an epistemological endeavour that speaks of knowledge production and the ways in which the world of social phenomena can be known. Of course it is intertwined also with the ontological and methodological discourse because it concerns the what (there is) and how (do we find out) questions. Postdisciplinarity, as we see it, is an invitation to conceptual and interpretive eclecticism, critical analysis, and creative problem solving. It extends to questioning conventional norms and processes of knowledge production, dissemination, and communication; it is an invitation to a debate about the genres that have received a privileged position in scholarly activities; and it challenges the established views about the scope and limits of what is possible, relevant, desirable, and even credible in academic terms. It is through the notion of art that we argue that "truth" is never absolute but elusive, constructed, and constituted by agreement. It is through the notion of academic freedom and play that we argue that tourism can be understood in different ways. Furthermore, it is through our personal journeys that we wish to communicate these early ideas about postdisciplinarity.

\section{Hot Spot Istanbul (by Tomas Pernecky)}

The idea for this article emerged when I was performing the role of a tourist on my way from the first Postdisciplinarity Conference in Neuchatel, in 2013, to the fifth Critical Tourism Studies Conference in Sarajevo, Bosnia, and Herzegovina. I had more than $12 \mathrm{hr}$ to occupy before catching my evening flight from Zurich, so I decided to spend the day visiting local museums and galleries. The highlight of the day was an exhibition called Hot Spot Istanbul, held at the Museum Haus Konstruktiv. It was described by the organizers as the first comprehensive exhibition of Turkish abstract, concrete, conceptual, and contemporary art in Switzerland. I have always been drawn to abstract art and objects that had somewhat hidden meaning-objects that make one work to find what it is they might convey. Before sketching a few important notions that I strongly associate with postdisciplinarity, and 
which can be better understood by drawing on art and my personal experiences, I begin by reflecting on a few events in my life. These memories are offered with the view to bring together some of the ideas in a richer and more meaningful way.

I grew up in a very functional block of apartments in one of the largest industrial cities in communist Czechoslovakia: Ostrava. At that time, Ostrava was famous for its steel industry and underground coal mines that earned it the name "the steel heart of the republic" (these have now become tourist attractions, museums, and national monuments). My mother was running a small cultural center, and my dad was working for a company that made chemicals. He also had a night job to provide additional income. After the Velvet Revolution in 1989 and with the fall of communism, new opportunities opened up, which were not possible for several decades. Within 2 years, my parents became entrepreneurs. My mother decided to open a small boutique shop, selling items that were not readily available on the market. Her business was very successful for many years, until the arrival of large shopping complexes that spread out throughout the country. This new phenomenon in the landscape of leisure activities was irresistible to most people and changed how they spent their free time. It also changed shopping style and buying behavior. City centers were no longer where people would go to meet their shopping needs. For the entrepreneurs, this meant that those who were not willing to pay large sums of money for lucrative rental spaces in shopping malls were about to face business hardship and loss of customers. Eventually, my mother's business went bankrupt.

During that time, there were many good moments, particularly in my younger years, that are worth recalling. When I was about 13 years old-approximately 2 years after the fall of communism-my mother took me and my brother on an overseas shopping trip. It was a 30 -hr bus voyage to Istanbul. It was also one of my first international tourism experiences. At that time, Istanbul was the best place to buy highly desirable items for bargain prices. I remember that spandex shorts in particular were in vogue and rather difficult to buy in the newly formed Czech Republic. Other popular items included blue and pink soaps with little magnets so that the soaps would adhere to the bath, leather jackets, T-shirts, underwear, sports shoes, and much more. The arrival in Istanbul was very exciting for me. We stayed in a hotel in the city center, close to all the shops and markets. The toilet in our room did not work, but the manager gave us a big smile and a bucket, showed us how to fill it up in the shower, and with one thumb up and the words “OK Technique?”, the problem was solved. The following day, I was taken by how different the place was. The incredible mosques; the way people looked, talked, and dressed; the endless "golden streets" full of shops offering items made of goldall of these were all a wonderful introduction to a new culture. I was allowed to buy a leather jacket that was three sizes too big; two 2-liter bottles of pink and blue shampoos, although I am at loss as to why because one could buy perfectly fine shampoos back home; and sports shoes that also were two sizes too large. I was in wonderland. Returning back home, our bus was filled with hundreds of socks, soaps, T-shirts, the desirable spandex shorts, and a myriad of other items. These were jammed under and above the seats and filled the back aisle of the bus. As we were passing through different borders on our way back, I learned that an inevitable part of these bus journey rituals was the bribery of custom officers. This had to be done in order to get through the borders without being made wait for hours, even days. Everyone accepted that the collection of monies was necessary to ensure the smooth administration.

Years later, before the eventual bankruptcy of my mother's business, and just before her unexpected passing in 2005, I asked her about the happiest moments of her life. I was interested to know because she experienced rather dramatic periods in the history of Czechoslovakia/the Czech Republic. Surprisingly, her most treasured days were during communism when she managed a small cultural center. There she was surrounded by creative people, and she worked with colleagues who appreciated beauty, music, art, and literature. She loved what she did and also the people she was surrounded by. All of this was sacrificed in the pursuit of new dreams and her becoming a business woman. F. Scott Fitzgerald (1920/1995) wrote in the novel This Side of Paradise the following about one of the characters: "it was always the becoming he dreamed of, never the being” (p. 24). 
I should note that the end of communism was also life-changing for my father. In his younger days, he used to paint and worked in a theatre where he was in charge of creating scenes for plays. After 1989, and a long career managing a unit in a chemical factory, my dad became an antique dealer. Because of his work, our apartment was filled with precious items, which I would then describe as old clutter. It is not that our home was a storage facility; only the valuable pieces found their way into the apartment. There were large Chinese vases, intricate coffee tables, the occasional statue, and many paintings. Slowly, some of these objects started to migrate to the room I shared with my brother. Fortunately, we were allowed to have a say in what we liked, and each negotiated the pieces to decorate our walls. The room became a battleground for different styles and tastes. In my corner were mostly abstract, cubist, and strange-looking paintings that did not necessarily convey any specific meaning. Among my favorites were two large human heads, filled with swirls and peculiar shapes by a Slovak painter, Stanislav Balko. There was also a painting of a clown made up of cubist shapes, and another one that consisted of a couple of legs resting in a sandy desert, a snake passing by, a cactus, a butterfly, and other objects that I cannot remember any longer. On the other side of the room was the exhibition of my brother's taste. Here one could find wooden-carved landscapes, painted landscapes, and portraits; among these items hung two carved wooden angels, which must have come from an old, disestablished church. This was our room.

\section{Istanbul in Zurich}

I have not visited Istanbul since the bus trip with my mom and my brother in 1991. When I saw that there was an exhibition on Istanbul in the Museum Haus Konstruktiv in Zurich, I thought it would be interesting to explore Turkish abstract art. I had seen many Czech, German, French, Slovak, Russian, and other paintings, but I did not know what Turkish art was like. The idea the organizers had for this exhibition was unique. I learned that it was not a representation of all Turkish abstract art; instead, the focus was on one city. The exhibition, shown over four floors, had 70 artworks, reaching back to post-1945. It brought together a number of artists, styles, and techniques, but the connecting link was the city of Istanbul. Apart from paintings, there were sculptures, drawings, videos, installations, and environments. All of these told a story through an incredible sensory experience. The pamphlet I picked up described it as follows:

in HOT SPOT ISTANBUL, many individual positions can be discovered, and each section of the exhibition claims autonomy. When observed in context, relationships between art history and the present day, as well as between different cultural influences, become clear. This is because it is primarily artists who have been, and are, frequently able to anticipate things with their works, thus bypassing not only the linear timeline, but also supposedly established cultural or art-historical attributions. (Hot Spot Istanbul Im Museum Haus Konstruktiv 6.6-22.9.2013)

The first point about postdisciplinarity I would like to make is related to what this exhibition sought to achieve. The thesis that postdisciplinarity, among other interpretations, is a phenomenonspecific inquiry was the premise of my talk in Neuchatel (Pernecky, 2013). The artist (we can say scholar) can mix and blend different styles in order to communicate what he or she sees is important, rather than depicting objective truths. This view is underpinned by the notion that there is not only one way of telling a story or one unanimous point of view. Truth, therefore, is a matter of fit- "fit to what is referred to in one way or another, or to other renderings, or to modes and manners of organization” (Goodman, 1978, p. 138). In this regard, tourism, and social reality at large, is built on collective intentionality. For a group of people to engage in tourism, there must be collective intentionality, cooperative behavior, and "we consciousness" (for a detailed explanation of these terms, see Searle, 1995). Postdisciplinarity recognizes that social realities are constructions in which we engage. It also recognizes that the stories told about such realities cannot be transcendentally true - that is, true "in all possible worlds of interpretation” (Gergen, 2009, p. 90). We agree socially, culturally, locally, historically, and conceptually on such truths. I use the word "phenomenon" in my work consciously and purposefully, and I offer it as an invitation to thinking about what something is and what else it may signify to different agents and/or observers—-before 
it is named, before it is given a label and fixed with a meaning. When we begin with the word "phenomenon," we are holding a blank canvas.

There is also a methodological and critical aspect to postdisciplinarity. The creative process of producing knowledge was described by Denzin and Lincoln (2000, p. 4) as bricolage: "a piecedtogether set of representations that are fitted to the specifics of a complex situation.” In this light, the postdisciplinary-inclined scholar is immersed in a very imaginative and artistic activity. He or she is not limited by a prevailing view or a doctrine that dictates how to best tackle the phenomenon he or she hopes to examine-that is, typically prescribed and predefined by the scholarly community to which he or she belongs. The aptitude of postdisciplinary research is in the reaching beyond the disciplinary strictures to unveil new understandings and to destabilize the "fixed." As I see it, the critical facet of postdisciplinarity can indulge in questions similar to a constructionist inquiry: "Whose tradition is being honoured in any given case? Whose values carry the day? What voices are absent?” (Gergen, 2009, p. 90). Of course, these problems are not new in the field of Tourism Studies (see, e.g., the work of Keith Hollinshead, including his contribution in this special issue), but when amalgamated with a postdisciplinary approach, the level of probing is allowed to occur on a much deeper level.

The methodological and epistemological freedom advocated by postdisciplinarity is not only important but necessary. It is necessary for the emergence of new creations, new interpretations, and new angles of vision. This is not to imply that tourism scholars are not creative or that they are deprived of academic freedom. This is not the point. The point rather is that every field or discipline, in order to become a field or a discipline, requires certain phenomena to be fixed and firmly secured so that they can become the defining features of that field or that discipline. This process is indeed important for the progress of disciplinary knowledge. However, once established, definitions and theories precondition academic tribes to "see" in certain ways. This then leads to preferred approaches and methods for maintaining academic truths. Disciplinary thinking tends to encourage practices that reinforce the survival of the discipline. Postdisciplinary thinking is critical and disobedient in this respect. It does not have to maintain any allegiance.

The kind of postdisciplinarity I have in mind does not suggest that we have to reject disciplinary, interdisciplinary, cross-disciplinary, and multidisciplinary approaches for a new ideal of knowledge production. Each offer valuable insights, levels of depth, and breadth. Postdisciplinary thinking recognizes that there are different ways of making sense of our worlds - it is a creative, critical, and disobedient endeavour, underpinned by methodological, epistemological, and semantic pluralism. Postdisciplinarity is also a counterresponse to those colleagues who find themselves wondering whether it is "enough that the result of social scientific inquiry is to empower a myriad of voices and to delight in documenting multiple representations of tourism" (Botterill, 2014, p. 292). However, would it not be a shame to not consider other representations? As I argued elsewhere (Pernecky, 2012, 2014), the world of tourism rests on social constructions. The study of tourism, therefore, is the study of such constructions. We have been busy building a catalogue of tourism according to which we classify people and behaviour; however, it would be unfortunate if we became too constrained by dogmatic, nonnegotiable attitudes. Thus, the postdisciplinary-inclined thinkers may see their role in the processes of knowledge-making as active story-tellers, facilitating and exploring multiple understandings. A research approach stemming from these epistemic and methodological values is far from an "anything goes" attitude-it is a critical and carefully mediated activity.

Returning to the exhibition I visited in Zurich, there are degrees of correspondence between postdisciplinarity and some of the pieces shown in the Museum Haus Konstruktiv. For instance, the artists Serhat Kiraz and Ahment Oktem are believed to be two of the most important representatives of minimal and conceptual art in Turkey. As explained by the organizers of the exhibition, they were the founding members of the "Art Definition Group" - an art movement in 1977-1978 that distanced itself from conventional art concepts. There were also other significant figures in post-1945 Turkish art, such as Nejad Melih Devrim, Mubin Orhon, Omer Uluc, and Fahrelnissa Zeid. Their work and approaches were described in the material presented in the museum as follows: 
Serhat Kiraz, for example, is not only interested in art and its history, but also in religion, archaeology, astronomy, astrology, philosophy and sociology. Thus, intellectual approaches from these domains are incorporated into his complex installations which, as a consequence, can only be deciphered gradually: star charts, I-Ching symbols or mathematical formulae provide a chain of associations which the observer, often in vain, tries to decode.

\begin{abstract}
Ahmet Oktem takes a different approach: in some of his works, he addresses the political systems in Turkey. For the work "untitled," which Oktem began to develop in the 1980s, he used copies of photos and letters from the Istanbul city archive. These served the employees as reference examples or guidelines, enabling them to adhere to the system of order in the archive. Removed from their original context and given a new code, the image panels and text panels in the museum can be ascribed new meanings.
\end{abstract}

Nejad Melih Devrim, Mubin Orhon, Omer Uluc, and Fahrelnissa Zeid: What connects the four is their exploration of the issue of what is actually still possible to show with painting (after the supposed end of painting) and of what the means are that let a painting become a painting. (Hot Spot Istanbul Im Museum Haus Konstruktiv 6.6-22.9.13.2013)

Artwork was also used as a means to challenge the audience by showing that new art can be created by deconstructing the "old." In this regard, the work of Ebru Uygun was a prime example of such complexity, mainly because everything that typically constitutes a painting is placed under scrutiny. Her method and philosophy was described as follows:

Uygun tears several previously painted canvases into strips, a process which is physically quite strenuous, and collages these strips in a new sequence on another canvas. In turn, this canvas is mounted very traditionally on a stretcher frame. The process of fragmentation and synthesis give rise to abstract constellations, the components of which hint at a possible, former whole, which nevertheless remains intangible. Thus the nonrepresentational fragments of forms and lines, which sometimes almost seem calligraphic, generate a kind of picture puzzle which, however, defies deciphering and leaves open the question of whether one of the paintings used was representational before its deconstruction. (Hot Spot Istanbul Im Museum Haus Konstruktiv 6.6-22.9.2013)
The aforementioned artists had to abandon the traditional notion of art; they decided to play with new concepts and approaches in order to create novel representations. Their determination to charter these new territories demanded the reexamination of not only what art is but also the processes of making and constructing it. Postdisciplinary-minded tourism researchers can adopt a similar attitude toward the once established tourism "givens"-embrace disobedience, creativity, original imaginaries, and conceptual and theoretical constructs that may reveal new peaks in the landscape of tourism phenomena.

In conclusion, there are many ways of explaining and understanding Istanbul. Istanbul can be experienced by a 13-year-old boy lost in awe of golden aisles, exotic foods, shops, and the hustle and bustle of a foreign city. Istanbul can also be experienced in Switzerland, where an entirely new layer of awareness can emerge by visiting an art exhibition. Istanbul, too, is constructed by tourist brochures, interpreted by tour guides, selectively represented by media, and promoted by the marketing machinery. What Istanbul is can never be established in one, true, objective account. It is constructed, reconstructed, and always changing, always evolving. Similar notions can be said of communism, citizenship, or the Czech Republic-a land that changed names, kings, regimes, language, borders, and power structures. Researchers may strive to group together certain behavior, assign it a label, and proclaim it to be the "truth." However, does that mean that there has to be only one truth? After all, do we not take part in many fleeting versions of the worlds we occupy? There does not have to be only one all-encompassing interpretation of all that exists, rather, "more than one interpretation of any infinitely complex world is always possible" (Hoy, 2010, p. 526).

\section{Afternote}

While working on this article, I received a phone call from my brother to say that my father is dying. Two days later I am in my old room in Ostrava. The paintings are different, the objects only vaguely familiar. It is not my room any more. It now belongs to my niece and nephews, for whom it has become their shelter. My dad passes away. As the days go by, 
the apartment is stripped bare, ready for sale. The objects that once occupied this space, the memories and experiences-all the meaningful stuff life is made of-now belong to the past. I find myself thinking: What is one to say of objectivity? Surely, it is the paintings, the vases, the wooden angels, and the stories that matter-yet, these are all gone. We can talk about essences, truth, and the absolute, but if we only dwell on that, we miss the point.

\section{My Shades of Gray: Going Beyond and} Reaching for Otherness (by Ana María Munar)

This is a story of identity, discovery, and idols: one that tries to express who I am and my fuzzy academic becomings, and, therefore, one that talks about sense-making and the meaning (or lack thereof) of knowledge production. It is a story about the possibility of knowledge.

Probably the question that I fear the most at academic gatherings is this: What is your research about? This question is bound to happen and is one that hides an immense complexity of an answer; it hides anxiety. So dear reader, how am I to introduce myself? I could say that I am a political scientist; however, despite my bachelor's and master's degrees on that discipline, I doubt this is appropriate. I do not feel entitled; it would be like stealing somebody else's jacket. Furthermore, if I had truly been a political scientist, I probably would not have felt the need to write this confessional piece. I can try with another "title": a tourism researcher and a disciplinary tourist. That's better. I feel entitled to be called both: a strange act of self-affirmation, because I do not have an official article to prove the former, and the latter only makes sense metaphorically. I happen to be a visitor of disciplines, the one that passes by. In my $\mathrm{PhD}$ title, it says "PhD in Economics and Business." That was the name of the $\mathrm{PhD}$ program I was enrolled at-a misleading fancy title (another stolen jacket?). At that time I was joyfully expecting my third child, my sweet Karen who is now 12 years old. I had recently moved from Copenhagen (Denmark) to Mallorca (Spain), because after years living abroad, I deeply missed my family and the Mediterranean, and although my fancy dream was to pursue doctoral studies in democratic theory, I finally enrolled in the $\mathrm{PhD}$ program that was available in that place and time of my life.
My doctoral thesis happened to be about globalization processes in tourism higher education, and not much managerial or economic disciplinary background was reflected in that work. That came later; many years of teaching at business programs and at a business school has made me closely acquainted to both. I have been working for more than a decade in departments dominated by economists-mostly male economists, the disciplinary residents. There should be a title for those that go through this kind of existential experience-an academic immigrant perhaps or legal alien. I would have liked to be able to call myself an expatriate: That would have been nice if only I knew which was the "patria” I was becoming an "ex" from. Researchers with disciplinary fatherlands respect each other. My story is one of postdisciplinarity identity and therefore one of awkwardness, the one that gets to you by being a minority and the periphery of your own academic institution. In my case, an immigrant in economy land, a hybrid. I did envy consolidated disciplinarybased identities - the powerful attraction of certainty and tradition, a solid ground to finally rest. Paradoxically, I felt also a powerful rejection of the same certainty; the solid ground seemed to me the one you could find in a graveyard. I saw disciplinarity as the fastest way to familiarization and narrow specialization, and I could intuitively perceive what research has long proven - that both tendencies turn out to be a real danger to creativity (Bilton, 2007). The discipline was to me an order and a system to be molded after. I wanted to play with disciplines instead of becoming one. However, the question at the core of this unrest remains, is it possible to be an academic without a discipline? A researcher without specialization or field of knowledge? A scholar without academy? Furthermore, does the idea of postdisciplinarity provide some light into this?

The story of my academic life is one of disjunctions, made of bits and pieces. A complex cocktail with a foundational body of knowledge obtained through my traditional and classic (old fashioned?) studies of political science. In Madrid at the end of the 1980s and beginning of the 1990s, students were still supposed to read all the classics: one book after another-Machiavelli, Hobbes, Marx, Weber (and research articles, what was that?). Those many hours of reading (sometimes boring reading, you 
know this if you also struggled through The Leviathan) are mixed with layers of my personal passions (literature, music, theater, film, art) and other texts gathered in my years in academia. This complex landscape is nurtured through personal relations (my mother's love for culture, my husband's passion for politics, the ways my coauthors tackle creative processes) and, not to forget, is shaped by random coincidences and specific practical demands. My first contact to tourism was when I was offered to teach some hours in a course on international tourism because there was nobody else that could do it that semester. These passions, coincidences, and demands enfold in nonlinear, not well planned incursions in territories of knowledge, but not only academic knowledge, in territories filled with artistic interpretations - oceans of music, waves of poems and novels, and horizons filled with images of paintings and movies.

Despite this complexity, the previous academic summary is only part of the story. Most of what goes on in my embodied and emotional relation to knowledge production has to do with me being raised in an environment of curiosity and appreciation for arts and culture. In my epistemic journeys, when I try to interpret and make sense of what is out there (the phenomenological) using the lenses of what is in here (my thinking processes; those languages, all that chemistry, blood, emotions; this limited brain, in this middle-age female body, in this space), disciplinary boundaries are not to be found anywhere. These journeys are essentially postdisciplinary (i.e., beyond disciplines; Coles, Hall, \& Duval, 2006). The issues that I am trying to grasp do not fit into one single discipline (e.g., humantechnology relationships or tourism), and the ways in which I try to make sense of those issues are through multiple interpretations and a mix of the scholarly, the artistic, and my feelings and perceptions. Despite this complexity, all of this diversity gets existentially integrated; it makes sense in me (or in you, in each one of us).

As you can imagine, with my understanding of what it is to be an academic, I should be doomed to exile and unrest, and so I was for a while; however, I feel myself increasingly happy and quite enjoying my nomadic existence in this "No Man's Land.” In the following, I want to share with you one artistic experience: the exhibition "Gerhard
Richter: Panorama.” This experience has beentogether with the reading of Margaret Atwood's (2002) essay Negotiating With the Dead: A Writer on Writing, and Mary Ruefle's (2012) lectures on poetry-a main source to my increased feeling of joy about epistemic journeys, about trying to make sense of the world. Richter, Atwood, and Ruefle, they are some of my idols.

\section{A Dawn in Gray}

In December 2011, I visited an exhibition at Tate Modern in London. Gerhard Richter: Panorama was a major chronological retrospective structured through a total of 13 rooms, each one dedicated to a particular moment of Richter's long artistic career. Gerhard Richter was born in 1932 in Dresden, at that time part of Communist East Germany. He crossed over to West Germany in 1961. As explained by the exhibitors, Richter's practice

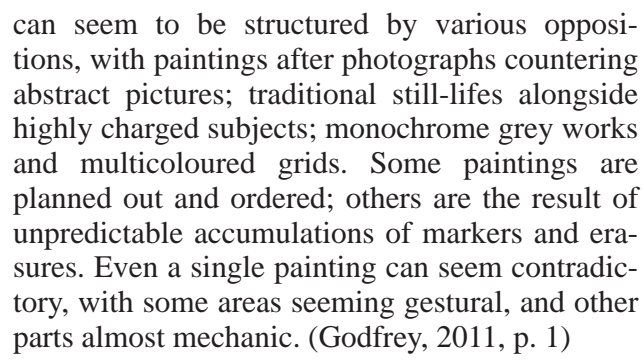

Walking through Richter's work was like crossing a landscape with breaks and new beginnings, with art works of an intense political character (e.g., the Baader-Meinhof paintings: 1988), others that were intensely sensual and intimate (e.g., the nude of his wife Ema: 1966; his daughter Betty: 1988), reinterpretations of the classical tradition of the "vanitas" — a call to reflection about the passing of time and the contemplation of death (e.g., skull: 1993; candle: 1982) — and a large variety of experimental abstractions (e.g., cage 1: 2006), landscapes that call to dream and fantasy (e.g., the clouds paintings: 1968-1979), mixed with other that confront the Nazi past (e.g., the Mustang squadron: 1964), and, of course, his grays.

Going from room to room, I got immersed in Richter's complexity. His career was a living expression of what Bourdieu has termed "artistic integrity." Artistic integrity describes an internal consistency 
both in the individual artistic career, in the work of art itself, and in the external relationships to the field of art (Bilton, 2007, p. 127). Despite the crossing of boundaries between genres, the processes of reinvention, and change of direction, still a strong sense of coherence prevailed. The works of art appeared as part of a coherent creative journey. I could mirror my own troublesome epistemological becoming in this type of artistic evolution, in the tension between diversity and being true to my own history. Postdisciplinarity entails academic integrity: embracing change with purpose and still aiming to keep a dialogue with the broader academic world. Richter's artistic journey made so much sense, much more than I had felt in all those departmental meetings throughout the years. I experienced this exhibition as an epistemological awakening. While slowly passing from one room to the other, I felt how Richter may also have had problems in answering what his art was about. He was not an abstract painter or a figurative painter; he was both nor neither.

The strongest impression of complexity and otherness in Richter's panorama came from his collection of gray paintings. I can clearly recall the feeling. There I was in the middle of the room surrounded by a multitude of expressions of gray-a collection of pieces of art that struck me as being the expression of nothing - wondering how a painter with the amazing technical ability of Richter had decided to do just that, a monochrome painting, square painted in gray. It was like imagining Mozart writing a musical composition with one single note. Why would one abandon one's skills, the one very thing that can differentiate one as artistic painter? And then I understood. It did make a lot of sense after all. Richter was using the ability that, in that very moment, he needed for a specific interpretation of the world; he was finding the expression that best matched his sense-making of a phenomenon. He abandoned his familiarization and his specialization to reach there. It was only later, while drinking a cup of coffee at the cafeteria of the museum, and in a strange state of mind, that I have entitled my "personal epistemic shock," that I read these sentences in the catalogue of the exhibition:

Richter worked on several series of grey monochrome paintings from the late 1960 s to the mid1970s. He wrote at the time that grey "makes no statement whatsoever; it evokes neither feelings nor associations; it is really neither visible nor invisible ... Grey is the welcome and only possible equivalent for indifference, noncommitment, absence of opinion, absence of shape.” Years later he suggested another dimension to these works: "grey monochrome paintings [were] the only way for me to paint concentration camps. It is impossible to paint the misery of life, except maybe in grey, to cover it.” (Godfrey, 2011, p. 6)

Now, when writing about this experience, I sense that the strong feeling of identification probably came from one single insight. Richter and I, each in our own ways, were both trying to internalize otherness. The internalization of otherness is another way to understand postdisciplinarity-a need to reach after and to playfully experiment how it must be to become the other. How will the world look from the perspective of the other, getting in love with otherness, and also trying to interpret the other? Knowledge production in social sciences is, after all, the textual interpretation of what a phenomenon means right now, right here, it is an instant shot, a photograph.

Mary Ruefle (2012) expressed the attraction of otherness so beautifully in her lecture "Poetry and the Moon.” This is a text so precious that I feel I am committing a sacrilege when cutting a piece of it. This deserves to be read in its entirety, but here it is, this single "sinful" quote:

the moon was the first poem, in the lyric sense, an entity complete in itself, recognizable at a glance, one that played upon the emotions so strongly that the context of time and place hardly seemed to matter. "Its power lies precisely in its remaining always on the verge of being 'read'” says Simic, speaking of photography, and I see the moon as the incunabulum of photography, as the first photograph, the first stilled moment, the first study in contrasts. Me here-you there. Now that's an interesting map-only I've got it all wrong. As Paul Auster points out in his novel Moon Palace, it really goes like this_- "You there-me here." (Ruefle, 2012, p. 15)

Sometimes to interpret and understand the world we, as researchers, need to be bold enough to abandon what is known to us, our skills, and what we are good at; we need to abandon our heritage and adopt other methods and tools of expression that will get us closer to the phenomenon 
we are trying to approach. Even if this means to cross or to abandon disciplines because there are moments when one single school of thought, or one single scholarly tradition, provides certainty but does not provide answers. We need to reflect on the questions that troubled Richter: What is it that we are not seeing, and what do we need to do to paint the gray in our canons of knowledge? Such reflexive processes resonate with the work of Richard Ek (2013) and Donna Chambers (2013). Ek, inspired by the theories of Annemarie Mol and John Law, made a call for an exploration of the absent-what is absent in our language and in our textual expressions of the existing, what is made invisible. Chambers called this a change in "epistemic grounding." She denounced how there is still a privileging of Western epistemologies in tourism that creates a boundary that largely excludes the voices of those in and from the South (i.e., the former colonized territories). We here, you there. "We" happen to be those that have the power of "truthful" interpretations, whereas the other is largely invisible or ignored.

In Habermas's words (another of my idols), reaching for the gray entails the establishment of "situations." A "situation" is a moment in communication where we question what is taken for granted, our own horizons of interpretation (Habermas, 1987). A moment of gray is the moment when we decide to cross over to the other side of the mirror. Margaret Atwood (2002) used "Alice Through the Looking Glass" as a metaphor of the existential doubleness of the writer. Alice is a story about the construction of alternate worlds and the expansion of horizons. Our act of writing about the world (in this case the world of tourism) entails doubleness; "the mere act of writing splits the self in two" (Atwood, 2002, p. 32). For what is the relationship between each one of us researchers with our complex selves-the person who exists when no research activity is taking place; walking, sleeping, cooking, laughingand us in the researcher "role" aiming to express life itself (our truths) through writings?

At the beginning of the story, Alice is on one side of the mirror - the "life" side, if you like-and the anti-Alice, her reflection and reverse double, is on the other, or "art" side. Like the Lady of Shalott, Alice is a mirror-gazer: the "life" side is looking in, the "art" side is looking out. But instead of breaking her mirror and thus discarding the "art" side for the hard and bright "life" side, where the "art" side is doomed to die, Alice goes the other way. She goes through the mirror, and then there is only one Alice, or only one we can follow. Instead of destroying her double, the "real" Alice merges with the other Alice - the imagined Alice, the dream Alice, the Alice who exists nowhere. And when the "life" side of Alice returns to the waking world, she brings the story of the mirror world back with her, and starts telling it to the cat ... The act of writing takes place at the moment when Alice passes through the mirror. At this one instant, the glass barrier between the doubles dissolves, and Alice is neither here nor there, neither art nor life, neither the one thing nor the other, though at the same time she is all of these at once. (Atwood, 2002, pp. 56-57)

And so it is the act of research. We cross mirrors to bring back stories, not to lose our "self" in the process (like in the fantasy of objectivism), but to enrich our and others' lives with new worlds. Alice represents both the courage and the curiosity that are needed to reach for the unknown. In many ways, we need to become children again in our search for insight, abandoning status and embracing playfulness. Richter's gray acted as a situation catalyst in my own academic mind set, a push toward crossing the mirror. His eclecticism and interpretation of the absent created a "situation," a breach in my personal horizon. Besides going beyond and reaching for otherness, the third dimension of postdisciplinarity is exactly this: the nurturing of critical thinking, the creation of situations, the questioning of the taken for granted, the reinventing of learnt skills and abilities, including the taken for granted of disciplinary truths. We may need to go beyond disciplinarity to keep academic integrity. We need to look up and reach for the moon.

\section{Choreographed Chaos: Random Reason (by Brian Wheeller)}

A couple of fortuitous coincidences, then, to set the current scene. Around the time this article was in its early, embryonic stage, and I was somewhat tentative as to participating ... unsure as to whether I had anything worthwhile to contribute ... I had just decided to have another go at tackling Wilde's (1890/2001) notorious The Picture of Dorian Gray . . . a book I had started several times, years ago, but had abandoned as, previously, I could not get into it at all. And 
there, early on, novel inspiration. "There is nothing that Art cannot express” (Wilde, 1890/2001, p. 11). So eloquent, so succinct, so perceptive. And, I thought, “a sign.” (Possibly, as things have subsequently transpired, misplaced. The reader can decide.)

The back cover of the Wordsworth edition of Wilde's (1890/2001) The Picture of Dorian Gray is also telling: "Wilde's only novel, first published in 1890 , is a brilliantly designed puzzle, intended to tease conventional minds with its exploration of the myriad interrelationships between art, life and consequences."

I had also been asked by Ilja Simons, an excellent colleague at NHTV (Breda, the Netherlands) to read a draft of "Sacred Stories and Silent Voices: What the Big Bad Wolf Can Tell Us," an article she was working on. In it she evocatively rewrites Grimm's "Little Red Riding Hood," this time from the "fearful" wolf's perspective. Simple but erudite, and (to me at least) an eye-opener, if ever there was one . . . enthusiastically encouraging the reader to look at a situation from a different, nontraditional, stereotypical perspective-and if this is not stimulating in itself, then what is?

There must be, I am sure, a plethora of academic material on "the fairy-tale of tainted innocence" ... much of it, unfortunately, probably now forever beyond my compass. However, reading Ilja's short piece prompted me (tangentially, as is often the way) to fish out an old Harry Chapin number (vinyl, I'm afraid ... age is, unfortunately, significant here) to be reassured by that inspirational wordsmith's immortal line: "My brain is still a virgin, though the rest of me's well done" (Chapin, 1976).

Did I say reassured? In fact, on second thought, confused. Because, on further reading, toward the end of Wilde's (1890/2001) libertine classic, one of the main characters laughingly asserts "If a man treats life artistically, his brain is his heart” (p. 170).

But isn't that where it should be, anyway? And doesn't this echo my late mum's wise words, "Follow your heart, love, not your head" forever lovingly, like sweet music, in my ear. Should they now have a hollow ring to them?

Well, no. For there, several days/daze later, while meandering through the maze of the Sunday papers, I stumbled upon a short, concise review of Saint Exupery's magical Little Prince, a tale I was totally unaware of until I was introduced to it years before through a fortuitous meeting with the impressive, enlightened individual and academic, Inna Petrun:

A children's book, but those of any age will be swept up in its wisdom. The prince falls to earth and is taught lessons we still never heed . . . One sees clearly only with the heart. What is essential is invisible to the eye. (Anonymous, 2013)

Were these "events" (Wilde, Simons, Grimm, Chapin, Petrun, Saint Exupery) serendipity? Reflection brought home to me that they were simply everyday, rather than extraordinary, occurrences ... reaffirming that the Arts, as a matter of course, play a dominant role in my thinking and concomitantly, in turn, influence (and, of late, increasingly determine) my research agenda. But nothing is straightforward-as by so doing this behavior seemingly contradicts "Art has no influence upon action" (Wilde, 1890/2001, p. 172).

One of Wilde's (1890/2001) characters also asserts, "He had no curiosity. It was his chief defect" (p. 168). What an indictment. For although curiosity might well have killed the cat, it presumably took it nine attempts to do so. And did not ex-Labour Leader Michael Foot paraphrase Wilde, when so astutely damning Margaret Thatcher? "She has no imagination, and that means no compassion" (Foot, n.d.). The clarion call here is for something different, maverick, perhaps best expressed with the maxim, "May the doors of imagination never close."

Something else cropped up recently that might (or might not) be relevant here. I was acting as external examiner for a PhD. In it, the candidate, no doubt tipped off as to his likely examiner, had (probably at the last minute) inserted in the "Personal Introduction," "Wheeller, who writes that academics should declare their interests and avoid notions of objectivity” (Jarratt, 2013). I went back to the original source and reread, reflected, reappraised, and reaffirmed my approach, which I now reiterate here. Subjective, rather than objective in perspective, I draw heavily on "the personal" in all my work. And, possibly, the irreverent.

Emotive subjectivity has, I believe, a vital, pivotal role to play in subject development. Research is moulded by prosaic resource and temporal considerations. And, of course, the researcher's personality, profile, and perspectives are paramount. Acknowledging and accepting this, surely we 
can accommodate (and celebrate) "the personal” as a positive.

Our sources should not be limited, blinkered, and restricted to academe alone. I contend we wholeheartedly embrace and interweave other eclectic points of reference, preferably from popular culture, into our work thereby, hopefully, enhancing "accessibility" of both thought and message.

Underlying all this has, of course, been my own background and associated values. Clearly, my upbringing and social life have been instrumental in determining my way of looking at "things." A baby-boomer, from a working-class background, suddenly in the 1960s, I was amazed to find myself at university. Far from the rebel, I was just grateful to be there, and I felt it was a wonderful opportunity, especially as so many of my friends remained stuck "behind" in Stockport, where many still are. Once immersed in Higher Education, for me it was, professionally, onward and upward-to where? Middle-age, middle-class, mediocrity? — while many of my friends back home took on manual, some might say, menial, jobs. And, to an extent, that is how it still is, decades later, today.

As a consequence, half my life is middle-class "professional," whereas the other half remains firmly rooted in working class culture and values. Simplistically, this schism, this dual existence is the shifting vantage point from which I question not only my own but the many values, and behavior, that others seem to presume the norm. The assumption appears to be that, as these are their own mores, automatically they are, therefore, the "norm," the benchmark, that all should aspire to and to judge others by. This manifests in the high/low culture "class" perspective and underpins much of my work and, in particular, was fundamental to my early analysis of the traveler/tourist/continuum, and the charade/canard of so-called sustainable tourism. "Brian Wheeller raised the problem of academics tending to concentrate on 'high culture' at the expense of 'low culture' and the latter's appeal to a broader base of tourists” (Towner, 1997, p. 1018).

Anyone glancing through this and finding it remotely interesting might want to take a look at an earlier effort, “Tourism and the Arts” (Wheeller, 2009)_a value laden, anecdotal perspective based on experience. "Rather than an objective, dispassionate, coherent, cogent analysis on the Arts and
Tourism I opted instead for a seemingly irreverent eclectic, erratic random ramble around the subject-a personal journey reflected in the thoughts aired and examples proffered by way of illustration" (Wheeller, 2009, p. 207). Is this a perfectly acceptable, alternative way of conducting research? Well, to me, "Yes." And worthwhile, though most, I am afraid, would doubt worthy: A "methodology" that probably warrants at least as much credence as some of the most sophisticated, but totally abstract, theoretical (often, but not necessarily, quantitative) approaches being prostituted as paradigms of excellence in the virtuous, austere realms of tourism research where publication (top refereed journals only, please) is, unfortunately, everything.

In the early 1980s, I enrolled in a part-time (evening/weekend) Master of Arts (MA) degree in American Studies. The primary motivation behind this was to explore the possibilities of nurturing an alternative perspective on "things." Even though my previous degrees had been in Economics, Applied Economics, and the Economic Impact of Tourism, I had never actually been comfortable with the economic paradigm, which I found disturbingly blinkered and restrictive. And I thought it prudent to attempt to see things through "different" eyes - more from an Arts dimension. This, indeed, proved to be the case. The MA was influential to my subsequent research output in that the course at Nottingham University was grounded in literature, politics, history, and geography; the dissertation on Anglo-American travel writing and the entire axis of the program were qualitative rather than quantitative. The prose of Nathaniel Hawthorne was soothing welcome relief, the perfect antidote to Archer's statistical machinations - my Master of Philosophy degree having been ensnared in Tourism Economic Multipliers. Maybe Lao Tzu's enigmatic, apposite quote "If you do not change direction, you may end up where you are heading” (as cited in Agarwal, 2013) has a certain resonance here.

Around this time I also attended evening classes on Travel Literature, which similarly proved seminal in that they introduced me to a wide range of eclectic literature that previously I had been unaware of-the works of, for example, Paul Fussell and Daniel J. Boorstin. And, in doing so, these works further facilitated the relatively easy task of weaning me off straight Economics. 
However, lingering damage had been inflicted. Despite my best efforts to the contrary, the dismal science still, occasionally, raises its ugly head in my vain search for "the truth."

Shortly before his assassination, John F. Kennedy (1963) declared "We must never forget that art is not a form of propaganda: it is a form of truth.” Forty years on, and of equal pertinent import, Robert Evans (2004), no doubt with similar conviction, stated "There are three sides to every story. Yours, mine and the truth" (p. 1). "Truth” at the best (and worst) of times is subjective: When it comes to "Art," Truth is not only subjective but, by its very nature, elusive. Beauty may, or may not, be in the Eye of the Beholder (or the Tourist?). When Art, as catalyst, is charged, as is increasingly the case in tourism, with an economic prerogative, the picture (never clear) becomes ever more opaque.

But then again, confusion is not necessarily a negative but often is a creative state of mind. Take some time out, sit back, and listen to Dobie (no relation to Dorian) Gray's (1973) haunting rendition of the wonderful "Drift Away" opening lines:

Day after day, I'm more confused

Yet I look for the light through the pouring rain.

Sublime.

\section{References}

Agarwal, A. (2013, June 16). Online universities: It’s time for teachers to join the revolution. Observer, p. 31.

Anonymous. (2013, October 6). One hundred books to love [Culture section]. Sunday Times, pp. 5-7.

Atwood, M. (2002). Negotiating with the dead: A writer on writing. New York, NY: Anchor Books.

Bilton, C. (2007). Management and creativity: From creative industries to creative management. Oxford, UK: Blackwell.

Botterill, D. (2014). Constructionism-A critical realist reply. Annals of Tourism Research, 48(5), 292-294. doi:10.1016/j.annals.2013.11.004

Chambers, D. (2013, October 24). Journeying beyond the frontiers of tourism knowledge. Keynote speech presented at the "Celebrating and Enhancing the Tourism Knowledge-Based Platform: A Tribute to Jafar Jafari” conference, Palma de Mallorca, Spain.

Chapin, H. (1976). On the road to kingdom come [Vinyl record]. Los Angeles, CA: Electra Records.

Coles, T. E., Hall, C. M., \& Duval, D. T. (2006). Tourism and post-disciplinary enquiry. Current Issues in Tourism, 9(4-5), 293-319.
Denzin, N. K., \& Lincoln, Y. S. (2000). Handbook of qualitative research (2nd ed.). London, UK: Sage.

Ek, R. (2013). Tourism social media as a fire object. In A. M. Munar, S. Gyimóthy, \& L. Cai (Eds.), Tourism social media: Transformations in identity, community and culture (Tourism Social Science Series, Vol. 18, pp. 19-34). Bingley, UK: Emerald.

Evans, R. (2004). The kid stays in the picture. New York, NY: New Millennium.

Fitzgerald, F. S. (1995). This side of paradise. Cambridge, UK: Cambridge University Press. (Original work published 1920)

Foot, M. (n.d.). Michael Foot quotes. Retrieved from http:// quotes.yourdictionary.com/author/michael-foot/51875

Gergen, K. J. (2009). Relational being: Beyond self and community. New York, NY: Oxford University Press.

Godfrey, M. (2011). Gerhard Richter, Panorama, 6 October 2011-8 January 2012 [Leaflet]. London, UK: Tate Modern.

Goodman, N. (1978). Ways of worldmaking. Indianapolis, IN: Hacket Publishing.

Gray, D. (1973). Drift away. On Drift away [Vinyl record]. Universal City, CA: MCA Records.

Habermas, J. (1987). The theory of communicative action (Vol. 2). Boston, MA: Beacon Press.

Hoy, D. C. (2010). One what? Relativism and poststructuralism. In M. Krausz (Ed.), Relativism: A contemporary anthology (pp. 524-535). New York, NY: Columbia University Press.

Jarratt, D. (2013). A socio-cultural analysis of the traditional seaside resort (Unpublished doctoral dissertation). University of Central Lancashire, Preston, UK.

Kennedy, J. (1963, October 26). President John F. Kennedy: Remarks at Amherst College [Transcript]. Retrieved from https://www.arts.gov/about/kennedy-transcript

Pernecky, T. (2012). Constructionism: Critical pointers for Tourism Studies. Annals of Tourism Research, 39(2), 1116-1137. doi:10.1016/j.annals.2011.12.010

Pernecky, T. (2013, June 19-22). Towards post-disciplinary ways of knowing. Symposium conducted at the "Welcoming Encounters: Tourism Research in a Postdisciplinary Era" conference, Neuchatel, Switzerland.

Pernecky, T. (2014). Realist and constructionist shades of grey. Annals of Tourism Research, 48(5), 295-298. doi:10.1016/j.annals.2014.06.011

Ruefle, M. (2012). Madness, rack and honey: Collected lectures. New York, NY: Wave Books.

Searle, J. R. (1995). The construction of social reality. New York, NY: The Free Press.

Towner, J. (1997). Tourism and culture. Annals of Tourism Research, 24(4), 1017-1019. doi:10.1016/S0160-7383 (97)88443-5

Wheeller, B. (2009). Tourism and the arts. In J. Tribe (Ed.), Philosophical issues in tourism (pp. 191-210). Bristol, UK: Channel View Publications.

Wilde, O. (2001). The picture of Dorian Gray. Ware, UK: Wordsworth Classics. (Original work published 1890) 